\title{
Per operative findings in repeat cesarean section
}

\author{
Parul Sinha $^{1}$ *, Uma Gupta ${ }^{1}$, Jyotsna Singh ${ }^{1}$, Anand Srivastava ${ }^{2}$, Shilpi Chauhan ${ }^{1}$
}

\author{
${ }^{1}$ Department of Obstetrics and Gynecology, Era's Lucknow Medical College and Hospital, Lucknow, India \\ ${ }^{2}$ Department of Respiratory Medicine, KGMU, Lucknow, India
}

Received: 27 January 2016

Revised: 02 February 2016

Accepted: 01 March 2016

\author{
*Correspondence: \\ Dr. Parul Sinha, \\ E-mail: drparulanand@gmail.com
}

Copyright: (c) the author(s), publisher and licensee Medip Academy. This is an open-access article distributed under the terms of the Creative Commons Attribution Non-Commercial License, which permits unrestricted non-commercial use, distribution, and reproduction in any medium, provided the original work is properly cited.

\begin{abstract}
Background: Cesarean section is the commonest obstetric procedure done worldwide. Incidence of cesarean section is increasing giving it a term "repeat cesarean section". Repeat cesarean section makes future obstetrics performances and abdominal exploration risky. After any Laparotomy it is fairly common to develop scar tissue, or adhesion. The scarring and adhesion formation is known to increase the major complications rate from $4.3 \%$ to $12.5 \%$ depending on the number of previous section. Intra peritoneal adhesions have an incidence of $5.5 \%$ to $42.5 \%$.

Methods: An observational prospective study was conducted in Obstetrics and gynecology department of Era's Lucknow Medical College, Lucknow. Total 80 cases of repeat cesarean sections were included. The case histories and intra operative findings were recorded.

Results: Intra peritoneal adhesions of varied types were seen in majority of cases, out of which the most commonly seen adhesion was between parietal peritoneum and anterior surface of uterus 24(30\%) and adhesion between bladder and uterus 24(30\%).

Conclusions: Chances of developing adhesions increases with each cesarean section, which leads to increase in morbidity of women. Thus cases of previous cesarean section should be educated about routine antenatal care.
\end{abstract}

Keywords: Repeat cesarean section, Maternal mortality, Intra peritoneal adhesions

\section{INTRODUCTION}

Cesarean section is the commonest obstetric procedure worldwide. ${ }^{1}$ It is an important and common surgical procedure that often saves the life of mother and baby. Its safety has increased with positive advances in surgical techniques as well as in patient care. ${ }^{1}$ The incidence of cesarean section is continuously rising giving it a term "Previous Cesarean Section". A lack of adequate contraceptive knowledge and the desire to have many children, especially in rural areas is the factor causing an increasing cesarean section incidence. Thus increased parity was found to be associated with adverse pregnancy outcome and to increase the cesarean section rate..$^{2-6}$ Repeat cesarean section makes future obstetrics performances and abdominal exploration risky. Cesarean section has several inherent complications but maternal and fetal wellbeing, timing of birth, the surgeon's experience and the infrastructure of the centre, the surgical technique and the risk of anesthesia are factors that play an important role in the emergence of complications. ${ }^{1}$ After any Laparotomy it is fairly common to develop scar tissue, or adhesion. The scarring and adhesion formation is known to increase the major complications rate from $4.3 \%$ to $12.5 \%$ depending on the number of previous section. ${ }^{8}$ Intraperitonial adhesions have an incidence of $5.5 \%$ to $42.5 \% .^{9}$ One major complication of repeat cesarean section is uterine scar rupture with subsequent adverse fetal and maternal consequences. Prior cesarean delivery forms a major complication for repeat cesarean deliveries and thus our study aimed at knowing the difficulties encountered in this highly prevalent surgical procedure. The aim and objectives of the study was to study the incidence and type of surgical difficulties encountered in women undergoing repeat cesarean section. 


\section{METHODS}

It is an observational prospective study conducted in obstetrics and gynecology department of Era's Lucknow Medical College and Hospital, Lucknow. In this study a total number of 80 cases of repeat cesarean section were included. The case histories of repeat cesarean section were studied and data regarding intra operative findings of all cases of repeat cesarean sections were recorded. The surgeons were requested to note in particular the difficulties they encountered while operating on cases of previous cesarean section. Information extracted included the maternal age, parity, indication of repeat cesarean section, number of previous cesarean section, type of cesarean section, type of abdominal and uterine incision and post-operative complications. Emergency cesarean was defined as an operative delivery carried out for unplanned reasons, and elective cesarean when, the operation was scheduled at 38 completed weeks of gestation. Pfannenstiel incision was performed in majority of patients, except those with previous vertical incision. Uterine scar dehiscence was defined as a window in the lower segment with intact peritoneum and membranes. Uterine rupture was diagnosed when fetal parts were found within the abdominal cavity after full thickness separation of the previous scar. Severe adhesions were considered, as the presence of adhesion detected intra operatively, extending from the abdominal wall to the bladder or to the front wall of the uterus, not separating easily and left alone during the surgery as much as possible due to the concern that it could cause serious morbidity. These adhesions interfere with the course of operation, increasing the time of operation, blood loss and maternal and fetal complications.

The research protocol was approved by the Institutional Ethics Committee before the study began. An informed consent was not needed as we noted down the peroperative findings written in the case sheets by the surgeon in-charge.

\section{Inclusion criteria}

1. All previous cesarean section irrespective of their number of previous cesarean section and type.

2. Women with previous cesarean section who have no history of any other abdominal surgery.

\section{Exclusion criteria}

All first time cesarean section, irrespective of their parity.

\section{Sample size}

Sample size is calculated on the basis of proportion of abdominal wall cicatrisation using the

Where, $\mathrm{p}=24.39$; Proportive of AWC; $\mathrm{q}=100-\mathrm{p}$; type 1 error $\alpha=5 \%$; allowed error $L=10 \%$; Data loss $=10 \%$. Thus sample size $\eta=80$.

\section{RESULTS}

Table 1: Indications of cesarean section in current pregnancy.

\begin{tabular}{|ll|}
\hline Indication & Cases \\
\hline Cephalo pelvic disproportion & $5(6.25 \%)$ \\
\hline Fetal distress & $19(23.5 \%)$ \\
\hline Severe PIH with fetal distress & $6(7.5 \%)$ \\
\hline Short interval pregnancy & $6(7.5 \%)$ \\
\hline Transverse lie & $5(6.25 \%)$ \\
\hline Breech & $2(2.5 \%)$ \\
\hline Placenta previa & $4(5 \%)$ \\
\hline PROM & $2(2.5 \%)$ \\
\hline Prolonged latent phase & $4(5 \%)$ \\
\hline Oligohydroamnios & $1(1.25 \%)$ \\
\hline
\end{tabular}

The main indication for performing a repeat cesarean section in current pregnancy was fetal distress $19(23.75 \%)$.

Table 2: Number of previous cesarean section.

\begin{tabular}{|ll|}
\hline No of previous C.S & Cases \\
\hline Previous 1 & $65(81.25 \%)$ \\
\hline Previous 2 & $14(17.5 \%)$ \\
\hline Previous 3 & Nil \\
\hline Previous 4 & $1(1.25 \%)$ \\
\hline No of previous C.S & Cases \\
\hline
\end{tabular}

Out of total 80 cases of previous cesarean sections 65 ( $840 \%$ patients were 2nd gravid $1.25 \%)$ were previous one cesarean section.

Table 3: Parity of the patients.

\begin{tabular}{|ll|}
\hline Parity & Cases \\
\hline Gravida 2 & $32(40 \%)$ \\
\hline Gravida3 & $28(5 \%)$ \\
\hline Gravida 4 & $14(17.5 \%)$ \\
\hline Gravid 5 & $6(7.5 \%)$ \\
\hline Parity & Cases \\
\hline
\end{tabular}

$40 \%$ patients were 2 nd gravid.

Table 4: Type of skin incision.

\begin{tabular}{|ll|}
\hline Skin incision & Cases \\
\hline Pfannensteil & $66(82.5 \%)$ \\
\hline Vertical to Para median & $6(7.5 \%)$ \\
\hline Para median to Vertical & $4(5 \%)$ \\
\hline Vertical & $2(2.5 \%)$ \\
\hline Johen Colen to Right Para median & $2(2.5 \%)$ \\
\hline
\end{tabular}

Out of total 80 cases of previous cesarean sections 65 $(81.25 \%)$ were previous one cesarean section, $14(17.5 \%)$ were previous two cesarean section and $1(1.25 \%)$ was previous four cesarean section. In 80 cases, $70(87.5 \%)$ were performed as an emergency procedure and rest were 
done on an elective basis. The main indication for performing a repeat cesarean section in current pregnancy was fetal distress 19 (23.75\%). Pfannensteil skin incision was given in majority of cases 66(82.5\%). In 10 (12.5\%) cases, skin incision was changed when compared to previous procedure. Intra peritoneal adhesions of varied types were seen in majority of cases, out of which the most commonly seen adhesion was between parietal peritoneum and anterior surface of uterus $24(30 \%)$ and adhesion between bladder and uterus 24(30\%). The adhesions not only slowed down the surgical procedure but also necessitated change of the surgeon to a more experienced one for reasons like separating dense adhesions, controlling blood loss, repair of bladder injury and uterine incision extension. Scar rupture was seen in 1 $(1.25 \%)$ and scar dehiscence 3 (3.75\%) cases respectively. Most common type of uterine scar was low transverse $42(52.5 \%)$. Need for obstetric hysterectomy was required in $3(3.75 \%)$ cases done for atonic PPH and one for placenta accreta.

Table 5: Type of adhesions.

\begin{tabular}{|ll|}
\hline $\begin{array}{l}\text { Type of Adhesion } \\
\text { Parietal peritoneum to anterior } \\
\text { surface of uterus }\end{array}$ & $24(30 \%)$ \\
\hline Parietal peritoneum to bladder & $15(18.75 \%)$ \\
\hline Parietal peritoneum to omentum & $14(17.5 \%)$ \\
\hline Omentum to uterus & $9(11.25 \%)$ \\
\hline Omentum to utero vesical fold & $2(2.5 \%)$ \\
\hline Bladder to uterus & $24(30 \%)$ \\
\hline Bladder to uterus advancement & $19(23.75 \%)$ \\
\hline Uterus to small bowel & $1(1.25 \%)$ \\
\hline Scar rupture & $1(1.25 \%)$ \\
\hline Scar dehiscence & $3(3.75 \%)$ \\
\hline
\end{tabular}

Table 6: Changes in uterine scar.

\begin{tabular}{|ll|}
\hline Changes in Uterine scar & Cases \\
\hline Low transverse to low transverse & $42(52.5 \%)$ \\
\hline Low transverse to high transverse & $34(42.5 \%)$ \\
\hline Low transverse to inverted T shaped & $4(5 \%)$ \\
\hline Low transverse to classical & NIL \\
\hline Classical to classical & NIL \\
\hline
\end{tabular}

\section{DISCUSSION}

Cesarean section is the commonest obstetric procedure worldwide. Modern obstetrics practice for medical, social, economic reasons has witnessed an increase in primary cesarean sections rates everywhere. This has created a common term; "Previous Cesarean Section" in subsequent pregnancies, giving a high risk pregnancy status to the subsequent pregnancy. ${ }^{1}$ This raises the issue of not only deciding the mode of delivery, vaginal birth after cesarean section (VBAC) or elective cesarean section, but also of difficulties in repeat procedure making it a high risk procedure. In developing countries where the antenatal care seeking rate is poor and last moment reporting is very high, makes the management of these cases very difficult and is managed on an emergency basis rather than ideal elective basis.

In our study the most common indication for performing repeat cesarean section was fetal distress 19 (23.75\%) which was comparable to other study where fetal distress was the second most common indication (19.51\%) after Cephalo pelvic disproportion (22.09\%). Repeated cesarean birth is related to serious maternal complication when compared to normal birth and first cesarean., ${ }^{72,14}$ Chances of developing adhesions increase with each cesarean section. Adhesions are a cause of acute morbidity with bleeding and increased surgery duration and of chronic morbidity, with chronic pelvic pain and intestinal problems. With increasing number of cesarean section the adhesion rate as well as intensity increases. In addition the adhesions can cause additional increase in morbidity directly or with peripheral organ injury. In our study the most common adhesion was between parietal peritoneum and anterior surface of uterus $24(30 \%)$ and bladder to uterus $24(30 \%)$ which is comparable to other study in which most common adhesion was between bladder and uterus (32\%) and parietal peritoneum to anterior surface of uterus (19\%). ${ }^{1}$ Abnormal placenta development following repeated cesarean birth is concurrent with an increased risk of placenta previa and placenta accreta. The risk of placenta previa has been reported to increase by $0.28 \%$ to $2 \%$ in patients who have undergone at least one cesarean section in a metaanalysis, including 36 studies. ${ }^{17}$ Hysterectomy is another significant morbidity. It is mostly associated with placenta accrete, placenta previa, uterine atony and uterine rupture. Each uterine scar is accompanied with an increasing risk of hysterectomy independent of the presence of placenta previa. ${ }^{15,18}$

\section{CONCLUSION}

Thus we come to a conclusion that cases of previous cesarean section should be educated about the need of routine antenatal care, need of last few visits to a tertiary level centre in order to decide the mode of delivery and to undergo elective or emergency cesarean section in a centre which is both better equipped and manned.

Here we conclude our study with a quote ${ }^{19}$

“Once a cesarean, always a caesarean” Cragin, 1916

“Once a cesarean, always a trial?” Pauerstein, 1966

“Once a cesarean delivery always a controversy" Flamm, $1997^{1}$

Funding: Not required

Conflict of interest: None declared

Ethical approval: The study was approved by the Institutional Ethics Committee 


\section{REFERENCES}

1. Mahale AR, Ghodke UP, Bhingare PE. Intraoperative difficulties in repeat cesarean sections- A study of 287 cases. J Obstet Gynecol India. 2008;58(6):507-10.

2. Kaplonoglu M, Atilla K, Utku A, Ali B. Complications and outcomes of repeat cesarean section in adolescent women. Int $\mathrm{J}$ Clin Exp Med. 2014;7:5621-8.

3. Qublan HS, Tahat MY. Multiple cesarean sections, the impact on maternal and fetal outcome. Saudi Med J. 2006:210-4.

4. Aziz FA. Pregnancy and lbor of grand multiparas soudanese women. Int $\mathrm{J}$ Gynecol Obstet. 1980;18:144-6.

5. Seidman DS, Armon Y, Roll D, Stevenson DK, Gale R. Grand multiparity: An obstetric or neonatal risk factor? Am J Obstet Gynecol. 1988;158:1034-19.

6. Qublan HS, Alghoweri AS, Abu-Khait S, Abu Salem A, Mehej A. Cesarean section Rate: the effect of age and parity. J Obstet Gynecol Res. 2002;28:22-5.

7. Kaplanoglu M, Bulbul M, Kaplanoglu D, Bakacak SM. Effect of multiple repeat cesarean sections on maternal morbidity: Data from Soth east Turkey: Mustafa Kaplanoglu Med Sci Monit. 2015;21:144753.

8. Nisenblat V, Barak S, Griness OB. Maternal complications associated with multiple cesarean deliveries. Obstet Gynecol. 2006;108:21-6.

9. Myers SA, Bennett TL. Incidence of significant adhesions at repeat cesarean section and the relationship to method of prior peritoneal closure. J Repord Med. 2005;50:659-62.

10. Sobande A, Eskandar M. Multiple repeat cesarean sections: complications and outcome. JOGC. 2006:193-7.

11. Khashoggi TY. Higher order multiple repeat cesarean sections; maternal and fetal outcome. Ann Saudi Med. 2003;23:278-82.

12. Leung AS, Leung EK, Paul RH. Uterine rupture after previous cesarean delivery; maternal and fetal consequences. Is J Obstet Gynecol. 1993;69:945-50.

13. Tampakoudis P. Cesarean section rates and indications in Greece: data from a 24 year period in a teaching hospital. Clin Exp Obstet Gynecol. 2004;31:289-92.

14. O'Dwyer V, Hogan JL, Farah N et al; maternal mortality and the rising cesarean rate. Int $\mathrm{J}$ Gynecol Obstet. 2012;116:54-6.

15. Tulandi T, Agdi M, Zarei A et al; adhesion development and morbidity after repeat cesarean delivery. Am J Obstet Gynecol. 2009;201:1-6.

16. Lyell DJ; Adhesions and perioperative complications of repeat cesarean delivery. Am J Obstet Gynecol. 2011;205:11-8.

17. Ananth CV, Smulian JC, Vintzileos AM; the association of placenta previa with history of cesarean delivery and abortion: a meta analysis. Am J Obstet Gynecol. 1997;177:1071-8.

18. Khong TY. The pathology of placenta accrete, a world wide epidemic. J Clin Pathol. 2008;6:1243-6.

19. William obstetrics; Prior cesarean delivery.F. Gary Cunningham: Mc Graw Hill; 24th edition; 2014:609.

Cite this article as: Sinha P, Gupta U, Singh J, Srivastava A, Chauhan S. Per operative findings in repeat cesarean section. Int J Reprod Contracept Obstet Gynecol 2016;5:1093-6. 